\title{
Outcome of intra-articular hyaluronic acid in treatment of osteoarthritis of knee at a tertiary care hospital in Kathmandu, Nepal
}

\author{
Dutta D \\ Department of Orthopedics \\ National Academy of Medical Sciences, Bir Hospital, Kathmandu, Nepal
}

\begin{abstract}
Background and Objectives: Intra-articular hyaluronic acid is widely used in the treatment of knee osteoarthritis. This study aimed to assess the efficacy of hyaluronic acid in moderate severity knee osteoarthritis.
\end{abstract}

Material and Methods: Patients of knee osteoarthritis were administered single intra-articular injection of Hyaluronic Acid $25 \mathrm{mg}$ (2.5 ml viscous solution) and were followed up at 4, 12, and 24 weeks. Functional improvement was assessed using Oxford Knee Score (OKS). Comparisons of preand post-intervention mean OKS scores were done by paired $t$ test.

Results: Total 50 patients (mean age $58.62 \pm 12.62$ years) were studied. In the six months follow up, patients showed marked improvement in functional outcome from a mean OKS of 27 before injection to 39 at 4 weeks and remained constant up to 6 months of follow up.

Conclusion: Intra-articular hyaluronic acid injectionas a treatment modality for moderate grade knee osteoarthritis provides good functional outcome and pain control for up to six months.

Key Words: Intraarticular Hyaluronic Acid, Knee Osteoarthritis, Oxford Knee Score.

\section{INTRODUCTION}

Osteoarthritis (OA) of the knee is a common degenerative joint disease that is characterized by loss of articular cartilage, subchondral bone sclerosis, osteophyte formation, changes in the synovial membrane, and reduced viscosity of synovial fluid.The incidence of disease increases with age and is a leading cause of disability in elderly.[1-3]Study shows that among elderly population over 60 years age, around $18 \%$ of women and over $10 \%$ men are affected $[4,5]$.
Among Asian population, the prevalence of OA knee is $6 \%$ in young over 30 years and $12 \%$ among elderly people over 65 years age $[6,7]$.

Osteoarthritis of knee is very common in Nepal due to its mountainous and hilly terrain and work condition of local populace. It has a significant impact among general population as it entails disability and healthcare costs. Pain and difficulty in 
walking, climbing stairs, and performing household chores are some of the disabilities. Symptomatic impact of knee osteoarthritis is estimated at 240/100,000 people per year[8]. Osteoarthritis prevalence rate is increasing in Nepal [9].

The treatment of osteoarthritis of knee is mainly focused on pain relief and improvement of joint function [10]. Surgical and non-surgical modalities are available. Though complex surgical procedures such as high tibial osteotomy and total knee replacements are effective, they are complex, expensive and not universally popular among local population. Non surgical options are myriad including weight reduction, physiotherapy, NSAIDs, and intra-articular injections of steroids.

Viscosupplementation with intra-articular hyaluronic acid (HA) is a novel pharmacological treatment for OA. HA exhibits various anti-inflammatory effects. It inhibits phagocytosis and leukocyte adherence, decreases inflammatory mediators, and release of arachidonic acid from synovial fibroblasts [11].

Clinical benefits of intra-articular $\mathrm{HA}$ is unlikely to be due to direct augmentation of synovial fluid elasticity and viscosity as the intra-articular half-life of injected HA is short, that is48 hours. However, studies show effects lasting up to a year after a single injection and HA concentration remaining increased up to 6 months post-injection with significantly increased visco-elasticity[12-15].

The objective of this study was to analyse the efficacy of intraarticularinjection of $\mathrm{HA}$ in patient with Grade II, III and IV knee osteoarthritis

\section{MATERIAL AND METHODS}

This study was conducted over a period of 18 months from December 2017 to June 2019at National Academy of Medical Sciences (NAMS),Bir Hospital and National Trauma Center,Kathmandu,Nepal.Patientsof knee osteoarthritis of moderate or higher grades not responding to conservative treatment with physiotherapy and anti-inflammatory drugs were enrolled for the study. Patients having blood coagulopathies, unfit medical conditions, local and systemic infections, and Kellgren-Lawrence (KL) grade I were excluded.[16]

Patients were given intra-articular injection of $25 \mathrm{mg}$ of high molecular weight hyaluronic acid (2.5 ml viscous solution) under aseptic precautions.The functional outcome was analyzed using Oxford KneeScore(OKS) which consists of 12 parameters encompassing knee function and pain scores.[17]

The mean OKS values before injection (preinjection) and at 4, 12, and 24 weeks of follow up visits were compared by paired t statistics, with level of significance set at 95\%, using software STATA IC16.

Informed written consent was obtained from the participants The study was approved by the Institutional Review Board of the NAMS.

\section{RESULTS}

The study was completed in total 50 patients; there was almost equal sex distribution. Their mean age was 58.62 years (range 40-85, standard deviation 12.62). Their general characteristics is given in Table 1. Majority of patients were of KL classification grade II knee osteoarthritis. About three fourths had primary osteoarthritis. 
The OKS scores before the intra-articular hyaluronic acid injection and at 4,12 , and 24 weeks of intervention were measured (figure 1). The paired $t$ comparison of the mean OKS scores before intervention to OKS score at 4 weeks showed very highly significant difference $(p=0.000)$ while the scores remained unchanged at weeks 12 and 24 weeks.

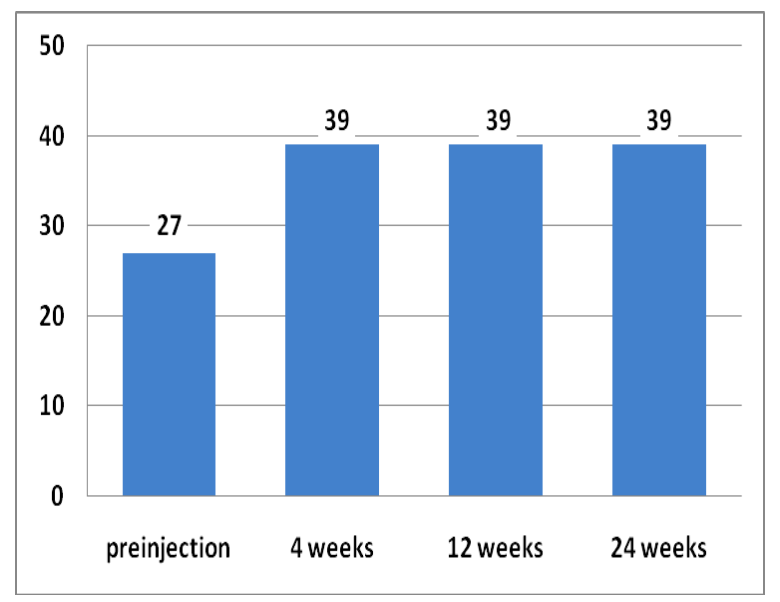

Figure 1: Means of $0 \mathrm{KS}$ before intervention and at different times of follow up

\begin{tabular}{|c|c|c|c|}
\hline \multicolumn{2}{|c|}{ Characteristics } & \multirow{2}{*}{$\begin{array}{r}\text { Number } \\
26\end{array}$} & \multirow{2}{*}{$\begin{array}{r}\text { Percentage } \\
52\end{array}$} \\
\hline Sex & Male & & \\
\hline & Female & 24 & 48 \\
\hline \multirow[t]{3}{*}{ K-L Class } & Grade II & 29 & 58 \\
\hline & Grade III & 17 & 34 \\
\hline & Grade IV & 4 & 8 \\
\hline \multirow{4}{*}{$\begin{array}{l}\text { Type of } \\
\text { pathology }\end{array}$} & Primary & 38 & 76 \\
\hline & $\begin{array}{l}\text { Secondary to } \\
\text { trauma }\end{array}$ & 7 & 14 \\
\hline & $\begin{array}{l}\text { Secondary to } \\
\text { rheumathoid } \\
\text { arthritis }\end{array}$ & 3 & 6 \\
\hline & $\begin{array}{l}\text { Secondary to } \\
\text { gout }\end{array}$ & 2 & 4 \\
\hline
\end{tabular}

\section{DISCUSSION}

This study aimed to assess the effectiveness of intra-articular HA injection in functional improvement in knee joint osteoarthritis. HA injections were given to patients with knee $\mathrm{OA}$ of grades II and above and who had significant disability, not improving from conservative treatment, not fit for operation due to medical factors, and preferring HA injection over operation for various reasons. Such patients usually resort to analgesics as a temporary measure for pain relief and tend to be dependent on them in order to continue with their normal activities of daily living. Sadly, long term complications of dependency on analgesics are detrimental to one's health $[18,19]$.

While intra-articular HA injection is recommended principally for moderate $\mathrm{OA}$ (KL grades II and III), there were 4 patients of grade IV severity (patients preferring HA injection over surgery) in this study. Significant improvement was noted at 4 weeks follow up which was sustained over the 6months (24 weeks) follow up. This demonstrates the effectiveness of single HA injection for at least 6 months and possibly beyond. Our findings are in agreement with study by Saturveithan et al which showed beneficial effect of intra-articular HA peaking at 2 months and remaining consistent till the end of study at 6 months.[20] Similar study by Yan et al showed maximum pain relief at 6 weeks post injection which remained constant until 6 months. They followed up the patients up to 1 year and found some increase in painlater which was yet significantly lower than pre-treatment level of pain [21].

The beneficiary effects of HA are attributed to the promotion of endogenous HA production and enhanced synthesis of extracellular 
matrix proteins, including chondroitin and keratin sulfate, and proteoglycans [13] HA also reduces the production and activity of various inflammatory mediators, including cytokines, proteases, and prostaglandins, and inhibits matrix metalloproteinase activity such that cell matrix synthesis is favored over degradation. Following injection, high molecular weight HA accumulates in cartilage and sub chondral bone [22]. Histological examination shows that it prevents degradation of cartilage and may promote its regeneration. In patients with symptomatic $\mathrm{OA}$ of the knee, HA injection protects knee cartilage [23].

Four patients (all primary, KL grade II) complained of swelling of the joint and increased pain following HA injection. The symptoms subsided in the next two to three days. No other significant injection-related adverse events were noted in our study.Webber et al have reported similar rates of adverse effects in the knees and have found no significant differencesin repeat injections as well [24].

\section{CONCLUSION}

In conclusion, intraarticular injection of hyaluronic acid has effective functional outcomes in moderate severity osteoarthritis for at least 6 months. Future studies with larger sample size and longer duration of follow up are required to draw robust conclusions. Also, larger studies would facilitate comparison of effectiveness in different severity classes of the patients.

\section{REFERENCES}

1. Doherty M, Lanyon P, Rolston SH. Musculoskeletal disorders. In: Boon NA, Colledge NR, Walker BR (eds).Davidson's Principles and practice of medicine. $20^{\text {th }}$ edn.
Churchill Livingstone: Edinburgh; 2006. pp 1065-1144.

2. Lawrence RC, Helmick CG, Arnett FC, et al. Estimates of the prevalence of arthritis and selected musculoskeletal disorders in the United States. Arthritis Rheum 1998; 41:778-799.

3. Towheed TE. The impact of musculoskeletal disorders in Canada. Ann Roy Coll Phys Surg Can 1998; 31:229-232.

4. Ma VY, Chan L, Carruthers KJ. Incidence, prevalence, costs, and impact on disability of common conditions requiring rehabilitation in the United States: stroke, spinal cord injury, traumatic brain injury, multiple sclerosis, osteoarthritis, rheumatoid arthritis, limb loss, and back pain. Arch Phys Med Rehabil. 2014;95(5):986.e1-995. DOI: 10.1016/j.apmr.2013.10.032

5. Woolf AD, Pfleger B. Burden of major musculoskeletal conditions. Bull World Health Organ. 2003;81(9):646-656.

6. Felson DT, Zhang Y. An update on the epidemiology of knee and hip osteoarthritis with a view to prevention. Arthritis Rheum 1998; 41:1343-1355.

7. Hinman RS, Bowles KA, Bennell KL. Laterally wedged insoles in knee osteoarthritis: do biomechanical effects decline after one month of wear? BMC Musculoskelet Disord 2009; 10:146. DOI: 10.1186/1471-2474-10-146.

8. Mahir L, Belhaj K, Zahi S, Azanmasso H, Lmidmani F, El Fatimi A. Impact of knee osteoarthritis on the quality of life. Annals of Physical and Rehabilitation Medicine. 2016;59:e159. DOI:10.1016/j.rehab.2016.07.355.

9. Neogi T. Joint pain epidemiology: fact sheet. International Association for the Study of Pain. 2016;(11).

10. Fibel KH, Hillstrom HJ, Halpern BC. State-ofthe-art management of knee osteoarthritis. World J Clin Cases 2015; 3(2):89-101.

11. Abate M, Salini V. Hyaluronic acid in the treatment of osteoarthritis: what is new? In: Chen Q (ed). Osteoarthritis - diagnosis, treatment and surgery. InTech: Rijeka; 2012. pp 102-122.

12. Brown TJ, Laurent UB, Fraser JR. Turnover of hyaluronan in synovial joints: elimination of labelled hyaluronan from the knee joint of the rabbit. Exp Physiol 1991;76(1):125-134.

13. Bagga H, Burkhardt D, Sambrook P, March L. Longterm effects of intraarticular hyaluronan on synovial fluid in osteoarthritis of the knee. $J$ Rheumatol 2006;33(5):946-950. 
14. Balazs EA, Denlinger JL. Viscosupplementation: a new concept in the treatment of osteoarthritis. J Rheumatol Suppl 1993;39(Suppl 39):3-9.

15. Pal S, Thuppal S, Reddy KJ, et al. Long-term (1year) safety and efficacy of a single 6-mL injection of Hylan G-F 20 in Indian patients with symptomatic knee osteoarthritis. Open Rheumatol J 2014;8:54-68.

16. Kohn MD, Sassoon AA, Fernando ND. Classification in brief: Kellgren-Lawrence classification of osteoarthritis. Clin Orthop Relat Res 2016; 474(8):1886-1893. DOI: 10.1007/s11999-016-4732-4

17. Charoencholvanich K, Pongcharoen B. Oxford Knee Score and SF-36: translation and reliability for use with total knee arthroscopy patients in Thailand. J Med Assoc Thai 2005; 88(9):1194202

18. Luyten F, Dell'accio F, De Bari C. Skeletal tissue engineering: opportunities and challenges. Best Pract Res Clin Rheumatol 2008; 15:7 59-69.

19. Flanigan DC, Harris JD, Trinh TQ, et al. Prevalence of chondral defects in athlete's knees a systematic review. Med Sci Sports Exerc 2010; 42:795-801.

20. Saturveithan C, Premganesh G, Fakhrizzaki S, et al. Intra-articular hyaluronic acid (HA) and platelet rich plasma (PRP) versus hyaluronic acid (HA) injection alone in patients with grade III and IV knee osteoarthritis (OA): a retrospective study on functional outcome. Malaysian Orthopaedic Journal 2016; 10(2):35-40. DOI: 10.5704/MOJ.1607.007

21. Yan CH, Chan WL, Yuen WH, et al.Efficacy and safety of Hylan G-F 20 injection in treatment of knee osteoarthritis in Chinese patients: results of a prospective, multicentre, longitudinal study. Hong Kong Med J 2015; 21(4):327-332. DOI: $10.12809 / \mathrm{hkmj} 144329$

22. du Souich P. Absorption, distribution and mechanism of action of SYSADOAS. Pharmacol Ther 2014;142(3):362-374.

23. Wang Y, Hall S, Hanna F, et al. Effects of Hylan G-F 20 supplementation on cartilage preservation detected by magnetic resonance imaging in osteoarthritis of the knee: a 2-year single-blind clinical trial. BMC Musculoskelet Disord 2011;12:195.

24. Webber TA, Webber AE, Matzkin E. Rate of adverse reactions to more than 1 series of viscosupplementation. Orthopaedics 2012, 35(4):e514-e519. DOI:10.3928/0147744720120327-26

\section{Correspondence to: Dr Deepak Kumar Dutta Department of Orthopedics, National Academy of Medical Sciences, Bir Hosppital, Kathmandu, Nepal Email: dr.deepakdutta@gmail.com}

